\title{
Proton drip-line nuclei in relativistic mean-field theory
}

\author{
G. A. Lalazissis and S. Raman \\ Physics Division, Oak Ridge National Laboratory, Oak Ridge, Tennessee 37831
}

(September 10, 2018)

\begin{abstract}
The position of the two-proton drip line has been calculated for even-even nuclei with $10 \leq Z \leq 82$ in the framework of the relativistic mean-field (RMF) theory. The current model uses the NL3 effective interaction in the meanfield Lagrangian and describes pairing correlations in the Bardeen-CooperSchrieffer (BCS) formalism. The predictions of the RMF theory are compared with those of the Hartree-Fock+BCS approach (with effective force Skyrme SIII) and the finite-range droplet model (FRDM) and with the available experimental information.
\end{abstract}

PACS numbers: 21.10.D, 21.10.F, 21.60.J

\section{INTRODUCTION}

Experimental and theoretical studies of exotic nuclei with extreme isospin values are active areas of current research in nuclear physics. The advent of radioactive beams and the creation of several facilities to produce them have provided the opportunities to study the structure and properties of very short-lived nuclei with extreme neutron-to-proton $(N / Z)$ ratios 四团.

On the neutron-rich side, exotic phenomena include (i) the weak binding of the outermost 
neutrons, (ii) pronounced effects of the coupling between bound states and the particle continuum, and (iii) regions of neutron halos with very diffuse neutron densities and major modifications in the shell structures. The situation is different on the proton-rich side of the stability valley. Here, nuclei are stabilized by the Coulomb barrier, which tends to localize the proton density in the nuclear interior, thereby preventing the formation of nuclei with large spatial extensions.

The opportunities provided by the radioactive beam facilities make the study of the structure and properties of nuclei close to the proton drip line a very interesting topic from both experimental and theoretical points of view. Experimentally, possibilities for studying new decay modes such as diproton emission have opened up. Theoretical studies allow further tests of the various models. Of special interest is the region of $s d-f p$-shell protonrich nuclei [8 11] where two-proton ground-state radioactivity 12 15] is expected to occur. In particular, the region around ${ }^{48} \mathrm{Ni}$ is expected to contain nuclei which are two-proton emitters.

In certain cases the proton drip line has been reached or even crossed experimentally. Systematic theoretical studies predicting the positions of the proton drip line are therefore important and timely [16]. In this work, the relativistic mean-field (RMF) theory is used to study the ground-state properties of very proton-rich, even-even nuclei with $10 \leq Z \leq 82$ and to predict the location of the two-proton drip line.

The RMF theory [17 20] has proven to be a powerful tool to describe and predict the properties of nuclei. This theory provides an elegant and economical framework, in which properties of nuclear matter and finite nuclei, as well as the dynamics of heavy-ion collisions, can be calculated (for a recent review, see Ref. [20]). Compared to conventional nonrelativistic approaches, relativistic models explicitly include mesonic degrees of freedom and describe the nucleons as Dirac particles. Moreover, the spin-orbit interaction arises naturally from the Dirac-Lorenz structure of the effective Lagrangian.

In this work, the calculations are performed in the axially-deformed configuration and the pairing correlations are accounted in the BCS formalism. It is known that the BCS 
description of the scattering of nucleonic pairs from bound states to the positive-energy particle continuum produces an unphysical component in the nucleon density with the wrong asymptotic behavior [21,22]. This effect is more pronounced for neutron-rich nuclei, for which the coupling to the particle continuum is particularly important. For proton-rich nuclei, however, the Coulomb barrier confines the protons in the interior of the nucleus. Therefore, the effect of the coupling to the continuum is weaker, and, for nuclei close to the proton drip line, the RMF+BCS approach can still be considered as a reasonable approximation providing sufficiently accurate solutions. Moreover, it has been shown in Ref. [10] that the total energy is not affected seriously by this coupling. Of course, it is more desirable if pairing correlations are described in the unified framework of the Relativistic-Hartree-Bogoliubov (RHB) scheme [or Hartree-Fock-Bogoliubov (HFB) in the nonrelativistic approach], in which the nucleon densities have the correct asymptotic behavior. However, numerical codes for deformed RHB calculations are not yet generally available. Those appearing in published RHB (HFB) studies use spherical configurations [10, 11,23, 26]. On the other hand, a detailed study of proton-rich nuclei within the deformed HF+BCS approach with the Skyrme effective force SIII has been reported recently [27].

The current paper is the first systematic study of the proton drip-line nuclei over a wide range of $Z$ values within the $\mathrm{RMF}+\mathrm{BCS}$ model. In Sec. II, a brief description of the RMF formalism is given, while in Sec. III, the results of our calculations are presented and discussed. Ground-state properties such as binding energies, two-proton separation energies, proton root-mean-square (rms) radii, and deformation parameters that result from fully selfconsistent RMF solutions have been calculated for very proton-rich nuclei near the proton drip line. Finally the prediction of the RMF theory for the location of the two-proton drip line is compared with those obtained from other theoretical models.

Strictly speaking, the proton drip line is delineated in a $Z$ vs. $N$ plot by nuclei with the smallest positive value of the proton separation energy $S_{1 p}$. To derive the global drip line, it is necessary to perform calculations for all nuclei, especially the odd- $Z$ and odd- $N$ ones. The RMF calculations for these nuclei are very involved and take prohibitively long computing 
times. Therefore, this work deals only with even-even nuclei and with the two-proton drip line defined by nuclei with the smallest positive value of the two-proton separation energy $S_{2 p}$. This restriction is not too severe because it can be shown that the drip lines defined by $S_{1 p}$ and $S_{2 p}$ are nearly parallel, except that nuclei specified by the $S_{1 p}$ line tends, on the average, to have one or two fewer nucleons than those specified by the $S_{2 p}$ line.

\section{THE RMF FORMALISM}

In relativistic quantum hadrodynamics the nucleons, described as Dirac particles, are coupled to exchange mesons and photon through an effective Lagrangian. The model is based on the one-boson exchange description of the nucleon-nucleon interaction. The Lagrangian density of the model is given by [20]

$$
\begin{aligned}
\mathcal{L}= & \bar{\psi}(i \gamma \cdot \partial-m) \psi+\frac{1}{2}(\partial \sigma)^{2}-U(\sigma) \\
& -\frac{1}{4} \Omega_{\mu \nu} \Omega^{\mu \nu}+\frac{1}{2} m_{\omega}^{2} \omega^{2}-\frac{1}{4} \overrightarrow{\mathrm{R}}_{\mu \nu} \overrightarrow{\mathrm{R}}^{\mu \nu}+\frac{1}{2} m_{\rho}^{2} \vec{\rho}^{2}-\frac{1}{4} \mathrm{~F}_{\mu \nu} \mathrm{F}^{\mu \nu} \\
& -g_{\sigma} \bar{\psi} \sigma \psi-g_{\omega} \bar{\psi} \gamma \cdot \omega \psi-g_{\rho} \bar{\psi} \gamma \cdot \vec{\rho} \vec{\tau} \psi-e \bar{\psi} \gamma \cdot A \frac{\left(1-\tau_{3}\right)}{2} \psi
\end{aligned}
$$

The Dirac spinor $\psi$ denotes the nucleon with mass $m$. The quantities $m_{\sigma}, m_{\omega}$, and $m_{\rho}$ are the masses of the $\sigma$ meson, the $\omega$ meson, and the $\rho$ meson, respectively, and $g_{\sigma}, g_{\omega}$, and $g_{\rho}$

are the corresponding coupling constants for the mesons to the nucleon. $U(\sigma)$ denotes the nonlinear $\sigma$ self-interaction [28],

$$
U(\sigma)=\frac{1}{2} m_{\sigma}^{2} \sigma^{2}+\frac{1}{3} g_{2} \sigma^{3}+\frac{1}{4} g_{3} \sigma^{4}
$$

and $\Omega^{\mu \nu}, \vec{R}^{\mu \nu}$, and $F^{\mu \nu}$ are field tensors 17 .

Assuming time-reversal symmetry and charge conservation, the coupled equations of motion are derived from the Langrangian density (1). The Dirac equation for the nucleons is

$$
\{-i \alpha \nabla+V(\mathbf{r})+\beta[M+S(\mathbf{r})]\} \psi_{i}=\epsilon_{i} \psi_{i}
$$


The Klein-Gordon equations for the mesons are

$$
\begin{aligned}
& \left\{-\Delta+m_{\sigma}^{2}\right\} \sigma(\mathbf{r})=\quad-g_{\sigma} \rho_{s}(\mathbf{r})-g_{2} \sigma^{2}(\mathbf{r})-g_{3}^{3}(\mathbf{r}), \\
& \left\{-\Delta+m_{\omega}^{2}\right\} \omega_{0}(\mathbf{r})=g_{\omega} \rho_{v}(\mathbf{r}), \\
& \left\{-\Delta+m_{\rho}^{2}\right\} \rho_{0}(\mathbf{r})=g_{\rho} \rho_{3}(\mathbf{r}), \\
& -\Delta A_{0}(\mathbf{r})=e \rho_{c}(\mathbf{r}) .
\end{aligned}
$$

The nucleon densities act as sources, and the contributions of negative-energy states are neglected (no-sea approximation [18]). More details on the RMF formalism can be found in Refs. [17 20].

\section{NUMERICAL RESULTS AND COMMENTS}

In this work, the Dirac equation for nucleons is solved using the method of oscillator expansion as described in Ref. [29]. Because most of the nuclei considered here are openshell nuclei, both proton and neutron pairing correlations have been included. The BCS formalism was used for the pairing with constant pairing gaps obtained from the prescription of Ref. [30]. The number of oscillator shells taken into account is 12 for fermionic and 20 for bosonic wave functions. The effective force NL3 was adopted for the calulations using a new version of the "axially-deformed" code 31. The parameter set NL3 has been derived recently [32] by fitting ground-state properties of ten spherical nuclei. Properties predicted with the NL3 effective interaction are found to be in good agreement with experimental data [32,33] for nuclei at and away from the line of $\beta$ stability.

The calculations have been performed for several nuclei close to the proton drip line for the even-even isotopic chains. In Table I the calculated total binding energies for the three most proton-rich isotopes close to the drip line are listed for each element with atomic numbers ranging from $Z=10$ to $Z=82$. The experimental values (in parentheses), if 
available, are also shown for comparison. With the exception of the binding energies for ${ }^{80} \mathrm{Zr},{ }^{100} \mathrm{Sn},{ }^{174} \mathrm{Hg}$, and ${ }^{180} \mathrm{~Pb}$, which are from Refs. 34 39], all other values are from the 1995 Atomic Mass Adjustment [40]. The rms deviation between calculation and experiment is only $3.1 \mathrm{MeV}$. The larger differences are observed for $N \approx Z$ nuclei. This observation might indicate that for these nuclei additional correlations should be taken into account 41]. In particular, proton-neutron pairing could have a strong influence on the masses. Proton-neutron short-range correlations are not included in our model.

In Fig. 1, the two-proton separation energies

$$
S_{2 p}(Z, N)=B(Z, N)-B(Z-2, N)
$$

are shown as function of the atomic number $Z$. In the upper panel are shown the two-proton separation energies $S_{2 p}$ for nuclei with $Z=10-48$, while in the lower panel are shown the corresponding values for nuclei with $Z=48-82$. Each curve corresponds to a given neutron number which changes from $N=8$ to $N=46$ (upper panel) and $N=48$ to $N=94$ (lower panel) in going from the left to the right of the figures.

In Table II are listed (first column) the predictions of the RMF theory for the most proton rich even-even nuclei (with $10 \leq Z \leq 82$ ) that are stable with respect to the twoproton emission, i.e., $S_{2 p}(Z, N)>0$. For comparison, the corresponding predictions of the HF+BCS mean-field theory (second column) with the effective force Skyrme SIII [27] and of the finite-range droplet model (FRDM) model 42,43] (third column) are also given. Finally in the fourth column the lightest experimentally known, proton-stable nuclei are listed for each even- $Z$ element. It is seen that the predictions of the various theoretical models are in accordance in most of the cases. Whether such close agreement exists in the neutron-rich region is an open question.

In Table III, the predictions of the RMF theory for the quadrupole deformation parameter $\beta_{2}$ are shown for all nuclei listed in the first column of Table I. It is seen that most of the nuclei close to the proton drip line are deformed, apart from those with magic proton (neutron) number, which are spherical or almost spherical. It turns out that the magic numbers 
maintain their character close to the proton drip line. In Fig. 2, the trend of the variation of the quadropole deformation parameter $\beta_{2}$ of the most proton-rich even-even nuclei that are stable to two-proton emission is shown as a function of $Z$.

Table III also gives the RMF predictions for the proton radii $r_{p}$. Unlike the other calculated ground-state properties, these $r_{p}$ values must be treated with some caution because, near the proton drip line, the BCS approach may not be a sufficiently good approximation for estimating proton radii.

In conclusion, a systematic study of the properties of very proton-rich nuclei close to the drip line has been carried out. The location of the two-nucleon proton drip line has been predicted, which is in agreement with the predictions of other theoretical models. In 14 of 37 cases (of even- $Z$ elements), the proton drip line has apparently been reached in a variety of experiments. The existing calculations (see Table II) suggest that there are approximately 60 unknown isotopes of even- $Z$ elements in the $10 \leq Z \leq 82$ region that are proton stable. The smallness of this number reflects the increased activity in this research area in recent years. The number of undiscovered isotopes in the neutron-rich side is, of course, much larger. Calculations similar to those reported here have been carried out by us for over 1300 even-even nuclei on either side of the valley of stability. These results will be reported separately.

\section{ACKNOWLEDGMENTS}

Helpful comments by C. Baktash, K. Rykaczewski, and W. Nazarewicz are acknowledged. The assistance of G. Audi in updating the experimental values given in Table I is also acknowledged. One of us (G.A.L) is grateful to the Joint Institute for Heavy-Ion Research for arranging his assignment to Oak Ridge. The current work was sponsored by the U.S. Department of Energy under Contract No. DE-AC05-96OR22464 with the Lockheed Martin Energy Research Corporation. 


\section{REFERENCES}

[1] E. Roeckl, Rep. Prog. Phys. 55, 1661 (1992).

[2] A. Mueller and B. Sherril, Annu. Rev. Nucl. Part. Sci. 43, 529 (1993).

[3] H. Geissel, G. Münzenberg, and K. Riisager, Annu. Rev. Nucl. Part. Sci. 45, 163 (1995).

[4] P. G. Hansen, A. S. Jensen, and B. Jonson, Annu. Rev. Nucl. Part. Sci. 45, 591 (1995).

[5] I. Tanihata, Progr. Part. Nucl. Phys. 35, 505 (1996).

[6] J. Vervier, Prog. Part. Nucl. Phys. 37, 435 (1996).

[7] Proceedings of the Fourth International Conference on Radioactive Nuclear Beams (Omiya, Japan), edited by S. Kubono, T. Kobayashi, and I. Tanihata, Nucl. Phys. A616 (1997).

[8] W. E. Ormand, Phys. Rev. C 53, 214 (1996).

[9] W. E. Ormand, Phys. Rev. C 55, 2407 (1997).

[10] W. Nazarewicz, J. Dobaczewski, T. R. Werner, J. A. Maruhn, P.-G. Reinhard, K. Rutz, C. R. Chinn, A. S. Umar, and M. R. Strayer, Phys. Rev. C 53, 740 (1996).

[11] D. Vretenar, G.A. Lalazissis, and P. Ring, Phys. Rev. C, in print.

[12] C. Détraz, R. Anne, P. Bricault, D. Guillemaud-Mueller, M. Lewitowicz, A. C. Mueller, Yu Hu Zhang, V. Borrel, J. C. Jacmart, F. Pougheon, A. Richard, D. Bazin, J. P. Dufour, A. Fleury, F. Hubert, and M. S. Pravikoff, Nucl. Phys. A519, 529 (1990).

[13] V. Borrel, R. Anne, D. Bazin, C. Borcea, G. G. Chubarian, R. Del Moral, C. Détraz, S. Dogny, J. P. Dufour, L. Faux, A. Fleury, L. K. Fifield, D. Guillemaud-Mueller, F. Hubert, E. Kashy, M. Lewitowicz, C. Marchand, A. C. Mueller, F. Pougheon, M. S. Pravikoff, M. G. Saint-Laurent, and O. Sorlin, Z. Phys. A 344, 135 (1992).

[14] B. Blank, S. Andriamonje, R. Del Moral, J. P. Dufour, A. Fleury, T. Josso, M. 
S. Pravikoff, S. Czajkowski, Z. Janas, A. Piechaczek, E. Roeckl, K.-H. Schmidt, K. Sümmerer, W. Trinder, M. Weber, T. Brohm, A. Grewe, E. Hanelt, A. Heinz, A. Junghans, C. Röhl, S. Steinhäuser, B. Voss, and M. Pfützner, Phys. Rev. C 50, 2398 (1994).

[15] B. Blank, S. Czajkowski, F. Davi, R. Del Moral, J. P. Dufour, A. Fleury, C. Marchand, M. S. Pravikoff, J. Benlliure, F. Boúe, R. Collatz, A. Heinz, M. Hellström, Z. Hu, E. Roeckl, M. Shibata, K. Sümmerer, Z. Janas, M. Karny, M. Pfützner, and M. Lewitowicz, Phys. Rev. Lett. 77, 2893 (1996).

[16] P. J. Woods and C. N. Davids, Annu. Rev. Nucl. Part. Sci. 47, 541 (1997).

[17] B. D. Serot and J. D. Walecka, Adv. Nucl. Phys. 16, 1 (1997).

[18] P. G. Reinhard, Rep. Prog. Phys. 52, 439 (1989).

[19] B. D. Serot, Rep. Prog. Phys. 55, 1855 (1992).

[20] P. Ring, Prog. Part. Nucl. Phys. 37, 193 (1996).

[21] J. Dobaczewski, H. Flocard, and J. Treiner, Nucl. Phys. A422, 103 (1984).

[22] J. Dobaczewski, W. Nazarewicz, T. R. Werner, J.-F. Berger, C. R. Chinn, and J. Dechargé, Phys. Rev. C 53, 2809 (1996).

[23] R. Smolańczuk and J. Dobaczewski, Phys. Rev. C 48, R2166 (1993).

[24] W. Nazarewicz, J. Dobaczewski, and T. R. Werner, Phys. Scr. T56, 9 (1995).

[25] J. Dobaczewski, W. Nazarewicz, and T. R. Werner, Z. Phys. A 354, 27 (1996).

[26] G. A. Lalazissis, D. Vretenar, W. Pöschl, and P. Ring, Nucl. Phys. A, in print.

[27] N. Tajima, S. Takahara, and N. Onishi, Nucl. Phys. A603, 23 (1996).

[28] J. Boguta and A. R. Bodmer, Nucl. Phys. A292, 413 (1977).

[29] Y. K. Gambhir, P. Ring, and A. Thimet, Ann. Phys. (N.Y.) 198, 132 (1990). 
[30] P. Möller and J. R. Nix, Nucl. Phys. A536, 20 (1992).

[31] P. Ring, Y. K. Gambhir, and G. A. Lalazissis, Comput. Phys. Commun. 105, 77 (1997).

[32] G. A. Lalazissis, J. König, and P. Ring, Phys. Rev. C 55, 540 (1997).

[33] G. A. Lalazissis, D. Vretenar, and P. Ring, Phys. Rev. C, in print.

[34] S. Issmer, M. Fruneau, J. A. Pinston, M. Asghar, D. Barnéoud, J. Genevey, Th. Kerscher, and K. E. G. Löbner, The European Physical Journal, in print.

[35] M. Chartier, G. Auger, W. Mittig, A. Lépine-Szily, L. K. Fifield, J. M. Casandjian, M. Chabert, J. Fermé, A. Gillibert, M. Lewitowicz, M. Mac Cormick, M. H. Moscatello, O. H. Odland, N. A. Orr, G. Politi, C. Spitaels, and A. C. C. Villari, Phys. Rev. Lett. 77, $2400(1996)$.

[36] K. Sümmerer, R. Schneider, T. Faestermann, J. Friese, H. Geissel, R. Gernhäuser, H. Gilg, F. Heine, J. Homolka, P. Kienle, H. J. Körner, G. Münzenberg, J. Reinhold, and K. Zeitelhack, Nucl. Phys. A616, 341c (1997).

[37] J. Uusitalo, M. Leino, R. G. Allatt, T. Enqvist, K. Eskola, P. T. Greenlees, S. Hurskanen, A. Keenan, H. Kettunen, P. Kuusiniemi, R. D. Page, and W. H. Trzaska, Z. Phys. A 358, 375 (1997).

[38] R. D. Page, P. J. Woods, R. A. Cunningham, T. Davinson, N. J. Davis, A. N. James, K. Livingston, P. J. Sellin, and A. C. Shotter, Phys. Rev. C 53, 660 (1996).

[39] K. S. Toth, J. C. Batchelder, D. M. Moltz, and J. D. Robertson, Z. Phys. A 355, 225 (1996).

[40] G. Audi and A. H. Wapstra, Nucl. Phys. A595, 409 (1995).

[41] N. Zeldes, in Handbook of Nuclear Properties, edited by D. Poenaru and W. Greiner (Clarendon, Oxford, 1996), p. 13. 
[42] P. Möller, J. R. Nix, W. D. Myers, and W. J. Swiatecki, At. Data Nucl. Data Tables 59, 185 (1995).

[43] P. Möller, J. R. Nix, and K.-L. Kratz, At. Data Nucl. Data Tables 66, 131 (1997). 


\section{TABLES}

TABLE I. Comparison of calculated and experimental binding energies (in $\mathrm{MeV}$ ) for some very proton-rich nuclei. Experimental values, where available, are displayed in parentheses. In our notation, $132.1532 \equiv 132.153 \pm 0.002,134.473 \equiv 134.47 \pm 0.03$, etc.

\begin{tabular}{|c|c|c|c|c|c|}
\hline${ }^{18} \mathrm{Ne}$ & $134.70(132.153$ 2) & ${ }^{68} \mathrm{Se}$ & 572.28 & ${ }^{124} \mathrm{Nd}$ & 1020.57 \\
\hline${ }^{20} \mathrm{Ne}$ & $155.51(160.6451)$ & ${ }^{68} \mathrm{Kr}$ & 544.35 & ${ }^{126} \mathrm{Nd}$ & 1042.02 \\
\hline${ }^{22} \mathrm{Ne}$ & $176.18\left(\begin{array}{lll}177.770 & 1\end{array}\right)$ & ${ }^{70} \mathrm{Kr}$ & 575.14 & ${ }^{128} \mathrm{Sm}$ & 1025.90 \\
\hline${ }^{20} \mathrm{Mg}$ & $136.62(134.47$ 3) & ${ }^{72} \mathrm{Kr}$ & $602.92(607.08$ 28) & ${ }^{130} \mathrm{Sm}$ & 1050.02 \\
\hline${ }^{22} \mathrm{Mg}$ & $166.97(168.578$ 2) & ${ }^{74} \mathrm{Sr}$ & 605.02 & ${ }^{132} \mathrm{Sm}$ & 1073.29 \\
\hline${ }^{24} \mathrm{Mg}$ & $194.51(198.2571)$ & ${ }^{76} \mathrm{Sr}$ & 634.86 & ${ }^{132} \mathrm{Gd}$ & 1050.66 \\
\hline${ }^{22} \mathrm{Si}$ & 136.94 & ${ }^{78} \mathrm{Sr}$ & $660.08(663.008$ 8) & ${ }^{134} \mathrm{Gd}$ & 1075.62 \\
\hline${ }^{24} \mathrm{Si}$ & $170.61(172.00420)$ & ${ }^{78} \mathrm{Zr}$ & 637.10 & ${ }^{136} \mathrm{Gd}$ & 1098.81 \\
\hline${ }^{26} \mathrm{Si}$ & 202.85 (206.046 3) & ${ }^{80} \mathrm{Zr}$ & $665.52(669.915)$ & ${ }^{136}$ Dy & 1075.72 \\
\hline${ }^{26} \mathrm{~S}$ & 171.17 & ${ }^{82} \mathrm{Zr}$ & $690.59(694.76)$ & ${ }^{138}$ Dy & 1099.89 \\
\hline${ }^{28} \mathrm{~S}$ & $207.28(209.41 \quad 17)$ & ${ }^{82} \mathrm{Mo}$ & 666.70 & ${ }^{140}$ Dy & 1122.86 \\
\hline${ }^{30} \mathrm{~S}$ & $239.98(243.6854)$ & ${ }^{84} \mathrm{Mo}$ & 696.05 & ${ }^{142} \operatorname{Er}$ & 1123.66 \\
\hline${ }^{32} \mathrm{Ar}$ & $244.56(246.385)$ & ${ }^{86} \mathrm{Mo}$ & $720.93(725.85)$ & ${ }^{144} \mathrm{Er}$ & 1147.01 \\
\hline${ }^{34} \mathrm{Ar}$ & $274.94(278.7214)$ & ${ }^{86} \mathrm{Ru}$ & 698.08 & ${ }^{146} \mathrm{Er}$ & 1171.18 \\
\hline${ }^{36} \mathrm{Ar}$ & $302.78(306.716$ 1) & ${ }^{88} \mathrm{Ru}$ & 726.42 & ${ }^{146} \mathrm{Yb}$ & 1147.13 \\
\hline${ }^{34} \mathrm{Ca}$ & 246.29 & ${ }^{90} \mathrm{Ru}$ & 755.03 & ${ }^{148} \mathrm{Yb}$ & 1172.49 \\
\hline${ }^{36} \mathrm{Ca}$ & $280.49(281.36 \quad 4)$ & ${ }^{90} \mathrm{Pd}$ & 729.27 & ${ }^{150} \mathrm{Yb}$ & 1197.32 \\
\hline${ }^{38} \mathrm{Ca}$ & $312.19(313.1225)$ & ${ }^{92} \mathrm{Pd}$ & 760.26 & ${ }^{152} \mathrm{Hf}$ & 1197.93 \\
\hline${ }^{40} \mathrm{Ti}$ & $314.07(314.4916)$ & ${ }^{94} \mathrm{Pd}$ & 789.17 & ${ }^{154} \mathrm{Hf}$ & 1221.51 \\
\hline${ }^{42} \mathrm{Ti}$ & $347.89(346.9056)$ & ${ }^{94} \mathrm{Cd}$ & 762.49 & ${ }^{156} \mathrm{Hf}$ & 1242.72 \\
\hline${ }^{44} \mathrm{Ti}$ & $372.30(375.4751)$ & ${ }^{96} \mathrm{Cd}$ & 794.21 & ${ }^{156} \mathrm{~W}$ & 1222.58 \\
\hline${ }^{44} \mathrm{Cr}$ & 350.43 & ${ }^{98} \mathrm{Cd}$ & 824.87 & ${ }^{158} \mathrm{~W}$ & 1244.50 \\
\hline${ }^{46} \mathrm{Cr}$ & $378.63(381.975$ 20) & ${ }^{98} \mathrm{Sn}$ & 797.11 & ${ }^{160} \mathrm{~W}$ & 1265.97 \\
\hline
\end{tabular}




\begin{tabular}{llllll}
${ }^{48} \mathrm{Cr}$ & $408.92(411.4628)$ & ${ }^{100} \mathrm{Sn}$ & $829.94(825.26)$ & ${ }^{160} \mathrm{Os}$ & 1244.57 \\
${ }^{46} \mathrm{Fe}$ & 351.34 & ${ }^{102} \mathrm{Sn}$ & 852.56 & ${ }^{162} \mathrm{Os}$ & 1267.07 \\
${ }^{48} \mathrm{Fe}$ & 383.65 & ${ }^{106} \mathrm{Te}$ & 874.22 & ${ }^{164} \mathrm{Os}$ & 1288.71 \\
${ }^{50} \mathrm{Fe}$ & $416.17(417.706)$ & ${ }^{108} \mathrm{Te}$ & $896.94(896.7016)$ & ${ }^{164} \mathrm{Pt}$ & 1267.40 \\
${ }^{50} \mathrm{Ni}$ & 385.20 & ${ }^{110} \mathrm{Te}$ & $918.42(919.446)$ & ${ }^{166} \mathrm{Pt}$ & 1289.23 \\
${ }^{52} \mathrm{Ni}$ & 418.66 & ${ }^{110} \mathrm{Xe}$ & 897.61 & ${ }^{168} \mathrm{Pt}$ & 1310.64 \\
${ }^{54} \mathrm{Ni}$ & $451.67(453.155)$ & ${ }^{112} \mathrm{Xe}$ & $921.11(921.6716)$ & ${ }^{170} \mathrm{Hg}$ & 1311.45 \\
${ }^{56} \mathrm{Zn}$ & 452.49 & ${ }^{114} \mathrm{Xe}$ & 943.73 & ${ }^{172} \mathrm{Hg}$ & 1333.42 \\
${ }^{58} \mathrm{Zn}$ & $484.68(486.965)$ & ${ }^{114} \mathrm{Ba}$ & 921.37 & ${ }^{174} \mathrm{Hg}$ & $1353.46(1354.743)$ \\
${ }^{60} \mathrm{Zn}$ & $510.89(514.99211)$ & ${ }^{116} \mathrm{Ba}$ & 946.82 & ${ }^{176} \mathrm{~Pb}$ & 1354.16 \\
${ }^{62} \mathrm{Ge}$ & 514.11 & ${ }^{118} \mathrm{Ba}$ & 970.50 & ${ }^{178} \mathrm{~Pb}$ & 1374.40 \\
${ }^{64} \mathrm{Ge}$ & $540.19(545.9526)$ & ${ }^{118} \mathrm{Ce}$ & 948.73 & ${ }^{180} \mathrm{~Pb}$ & $1394.17(1390.653)$ \\
${ }^{66} \mathrm{Ge}$ & $564.71(569.294)$ & ${ }^{120} \mathrm{Ce}$ & 974.03 & & \\
${ }^{64} \mathrm{Se}$ & 514.40 & ${ }^{122} \mathrm{Ce}$ & 997.93 & & \\
${ }^{66} \mathrm{Se}$ & 544.10 & ${ }^{122} \mathrm{Nd}$ & 975.49 & & \\
\hline \hline
\end{tabular}


TABLE II. Predictions of the RMF theory for the most proton-rich, even-even, proton-stable nuclei with $10 \leq Z \leq 82$. Predictions of the HF+BCS mean-field theory and of the FRDM model are also shown. In the last column are listed the most proton-rich nuclei known experimentally.

\begin{tabular}{|c|c|c|c|}
\hline Calculation & Calculation & Calculation & \\
\hline $\mathrm{RMF}+\mathrm{BCS}$ & $\mathrm{HF}+\mathrm{BCS}$ 27] & FRDM 42,43 & Experiment \\
\hline (NL3) & (SIII) & & \\
\hline${ }^{18} \mathrm{Ne}$ & ${ }^{18} \mathrm{Ne}$ & ${ }^{18} \mathrm{Ne}$ & ${ }^{16} \mathrm{Ne}$ \\
\hline${ }^{20} \mathrm{Mg}$ & ${ }^{20} \mathrm{Mg}$ & ${ }^{20} \mathrm{Mg}$ & ${ }^{20} \mathrm{Mg}$ \\
\hline${ }^{22} \mathrm{Si}$ & ${ }^{22} \mathrm{Si}$ & ${ }^{24} \mathrm{Si}$ & ${ }^{22} \mathrm{Si}$ \\
\hline${ }^{26} \mathrm{~S}$ & ${ }^{26} \mathrm{~S}$ & ${ }^{28} \mathrm{~S}$ & ${ }^{27} \mathrm{~S}$ \\
\hline${ }^{32} \mathrm{Ar}$ & ${ }^{32} \mathrm{Ar}$ & ${ }^{32} \mathrm{Ar}$ & ${ }^{31} \mathrm{Ar}$ \\
\hline${ }^{34} \mathrm{Ca}$ & ${ }^{34} \mathrm{Ca}$ & ${ }^{36} \mathrm{Ca}$ & ${ }^{35} \mathrm{Ca}$ \\
\hline${ }^{40} \mathrm{Ti}$ & ${ }^{40} \mathrm{Ti}$ & ${ }^{40} \mathrm{Ti}$ & ${ }^{39} \mathrm{Ti}$ \\
\hline${ }^{44} \mathrm{Cr}$ & ${ }^{43} \mathrm{Cr}$ & ${ }^{44} \mathrm{Cr}$ & ${ }^{43} \mathrm{Cr}$ \\
\hline${ }^{46} \mathrm{Fe}$ & ${ }^{46} \mathrm{Fe}$ & ${ }^{48} \mathrm{Fe}$ & ${ }^{45} \mathrm{Fe}$ \\
\hline${ }^{50} \mathrm{Ni}$ & ${ }^{50} \mathrm{Ni}$ & ${ }^{50} \mathrm{Ni}$ & ${ }^{49} \mathrm{Ni}$ \\
\hline${ }^{56} \mathrm{Zn}$ & ${ }^{56} \mathrm{Zn}$ & ${ }^{56} \mathrm{Zn}$ & ${ }^{57} \mathrm{Zn}$ \\
\hline${ }^{62} \mathrm{Ge}$ & ${ }^{60} \mathrm{Ge}$ & ${ }^{62} \mathrm{Ge}$ & ${ }^{61} \mathrm{Ge}$ \\
\hline${ }^{64} \mathrm{Se}$ & ${ }^{64} \mathrm{Se}$ & ${ }^{66} \mathrm{Se}$ & ${ }^{66} \mathrm{Se}$ \\
\hline${ }^{68} \mathrm{Kr}$ & ${ }^{68} \mathrm{Kr}$ & ${ }^{70} \mathrm{Kr}$ & ${ }^{71} \mathrm{Kr}$ \\
\hline${ }^{74} \mathrm{Sr}$ & ${ }^{72} \mathrm{Sr}$ & ${ }^{74} \mathrm{Sr}$ & ${ }^{73} \mathrm{Sr}$ \\
\hline${ }^{78} \mathrm{Zr}$ & ${ }^{76} \mathrm{Zr}$ & ${ }^{78} \mathrm{Zr}$ & ${ }^{79} \mathrm{Zr}$ \\
\hline${ }^{82} \mathrm{Mo}$ & ${ }^{80} \mathrm{Mo}$ & ${ }^{84} \mathrm{Mo}$ & ${ }^{83} \mathrm{Mo}$ \\
\hline${ }^{86} \mathrm{Ru}$ & ${ }^{82} \mathrm{Ru}$ & ${ }^{86} \mathrm{Ru}$ & ${ }^{87} \mathrm{Ru}$ \\
\hline${ }^{90} \mathrm{Pd}$ & ${ }^{88} \mathrm{Pd}$ & ${ }^{90} \mathrm{Pd}$ & ${ }^{91} \mathrm{Pd}$ \\
\hline${ }^{94} \mathrm{Cd}$ & ${ }^{92} \mathrm{Cd}$ & ${ }^{94} \mathrm{Cd}$ & ${ }^{97} \mathrm{Cd}$ \\
\hline${ }^{98} \mathrm{Sn}$ & ${ }^{96} \mathrm{Sn}$ & ${ }^{98} \mathrm{Sn}$ & ${ }^{100} \mathrm{Sn}$ \\
\hline
\end{tabular}




\begin{tabular}{|c|c|c|c|}
\hline${ }^{106} \mathrm{Te}$ & ${ }^{108} \mathrm{Te}$ & ${ }^{108} \mathrm{Te}$ & ${ }^{106} \mathrm{Te}$ \\
\hline${ }^{110} \mathrm{Xe}$ & ${ }^{110} \mathrm{Xe}$ & ${ }^{110} \mathrm{Xe}$ & ${ }^{110} \mathrm{Xe}$ \\
\hline${ }^{114} \mathrm{Ba}$ & ${ }^{114} \mathrm{Ba}$ & ${ }^{114} \mathrm{Ba}$ & ${ }^{114} \mathrm{Ba}$ \\
\hline${ }^{118} \mathrm{Ce}$ & ${ }^{118} \mathrm{Ce}$ & ${ }^{118} \mathrm{Ce}$ & ${ }^{121} \mathrm{Ce}$ \\
\hline${ }^{122} \mathrm{Nd}$ & ${ }^{122} \mathrm{Nd}$ & ${ }^{122} \mathrm{Nd}$ & ${ }^{127} \mathrm{Nd}$ \\
\hline${ }^{128} \mathrm{Sm}$ & ${ }^{128} \mathrm{Sm}$ & ${ }^{128} \mathrm{Sm}$ & ${ }^{131} \mathrm{Sm}$ \\
\hline${ }^{132} \mathrm{Gd}$ & ${ }^{132} \mathrm{Gd}$ & ${ }^{134} \mathrm{Gd}$ & ${ }^{135} \mathrm{Gd}$ \\
\hline${ }^{136}$ Dy & ${ }^{136} \mathrm{Dy}$ & ${ }^{138} \mathrm{Dy}$ & ${ }^{141}$ Dy \\
\hline${ }^{142} \operatorname{Er}$ & ${ }^{142} \mathrm{Er}$ & ${ }^{144} \mathrm{Er}$ & ${ }^{145} \mathrm{Er}$ \\
\hline${ }^{146} \mathrm{Yb}$ & ${ }^{148} \mathrm{Yb}$ & ${ }^{148} \mathrm{Yb}$ & ${ }^{150} \mathrm{Yb}$ \\
\hline${ }^{152} \mathrm{Hf}$ & ${ }^{152} \mathrm{Hf}$ & ${ }^{154} \mathrm{Hf}$ & ${ }^{154} \mathrm{Hf}$ \\
\hline${ }^{156} \mathrm{~W}$ & ${ }^{156} \mathrm{~W}$ & ${ }^{158} \mathrm{~W}$ & ${ }^{158} \mathrm{~W}$ \\
\hline${ }^{160} \mathrm{Os}$ & ${ }^{162} \mathrm{Os}$ & ${ }^{162} \mathrm{Os}$ & ${ }^{162} \mathrm{Os}$ \\
\hline${ }^{164} \mathrm{Pt}$ & ${ }^{166} \mathrm{Pt}$ & ${ }^{170} \mathrm{Pt}$ & ${ }^{166} \mathrm{Pt}$ \\
\hline${ }^{170} \mathrm{Hg}$ & ${ }^{172} \mathrm{Hg}$ & ${ }^{174} \mathrm{Hg}$ & ${ }^{174} \mathrm{Hg}$ \\
\hline${ }^{176} \mathrm{~Pb}$ & ${ }^{176} \mathrm{~Pb}$ & ${ }^{180} \mathrm{~Pb}$ & ${ }^{180} \mathrm{~Pb}$ \\
\hline
\end{tabular}


TABLE III. Predictions of the RMF theory for the proton radii $\left(r_{p}\right)$ and quadrupole deformation parameters $\left(\beta_{2}\right)$ for proton-rich nuclei close to the proton drip line.

\begin{tabular}{|c|c|c|c|c|c|c|c|c|}
\hline Nucleus & $r_{p}$ & $\beta_{2}$ & Nucleus & $r_{p}$ & $\beta_{2}$ & Nucleus & $r_{p}$ & $\beta_{2}$ \\
\hline${ }^{18} \mathrm{Ne}$ & 2.959 & 0.001 & ${ }^{68} \mathrm{Se}$ & 4.010 & -0.285 & ${ }^{124} \mathrm{Nd}$ & 4.854 & 0.341 \\
\hline${ }^{20} \mathrm{Ne}$ & 2.911 & 0.186 & ${ }^{68} \mathrm{Kr}$ & 4.075 & -0.274 & ${ }^{126} \mathrm{Nd}$ & 4.862 & 0.339 \\
\hline${ }^{22} \mathrm{Ne}$ & 2.892 & 0.350 & ${ }^{70} \mathrm{Kr}$ & 4.087 & -0.310 & ${ }^{128} \mathrm{Sm}$ & 4.905 & 0.346 \\
\hline${ }^{20} \mathrm{Mg}$ & 3.120 & 0.002 & ${ }^{72} \mathrm{Kr}$ & 4.103 & -0.358 & ${ }^{130} \mathrm{Sm}$ & 4.911 & 0.343 \\
\hline${ }^{22} \mathrm{Mg}$ & 3.076 & 0.356 & ${ }^{74} \mathrm{Sr}$ & 4.195 & 0.387 & ${ }^{132} \mathrm{Sm}$ & 4.920 & 0.341 \\
\hline${ }^{24} \mathrm{Mg}$ & 3.021 & 0.416 & ${ }^{76} \mathrm{Sr}$ & 4.207 & 0.410 & ${ }^{132} \mathrm{Gd}$ & 4.954 & 0.346 \\
\hline${ }^{22} \mathrm{Si}$ & 3.266 & -0.001 & ${ }^{78} \mathrm{Sr}$ & 4.213 & 0.417 & ${ }^{134} \mathrm{Gd}$ & 4.959 & 0.344 \\
\hline${ }^{24} \mathrm{Si}$ & 3.186 & 0.230 & ${ }^{78} \mathrm{Zr}$ & 4.272 & 0.422 & ${ }^{136} \mathrm{Gd}$ & 4.985 & 0.359 \\
\hline${ }^{26} \mathrm{Si}$ & 3.133 & 0.320 & ${ }^{80} \mathrm{Zr}$ & 4.276 & 0.437 & ${ }^{136} \mathrm{Dy}$ & 4.998 & 0.345 \\
\hline${ }^{26} \mathrm{~S}$ & 3.332 & 0.001 & ${ }^{82} \mathrm{Zr}$ & 4.205 & -0.232 & ${ }^{138}$ Dy & 5.012 & 0.346 \\
\hline${ }^{28} \mathrm{~S}$ & 3.270 & 0.268 & ${ }^{82} \mathrm{Mo}$ & 4.256 & -0.230 & ${ }^{140} \mathrm{Dy}$ & 5.017 & 0.326 \\
\hline${ }^{30} \mathrm{~S}$ & 3.205 & -0.224 & ${ }^{84} \mathrm{Mo}$ & 4.258 & -0.247 & ${ }^{142} \mathrm{Er}$ & 5.036 & 0.297 \\
\hline${ }^{32} \mathrm{Ar}$ & 3.333 & -0.145 & ${ }^{86} \mathrm{Mo}$ & 4.241 & 0.003 & ${ }^{144} \mathrm{Er}$ & 5.033 & 0.257 \\
\hline${ }^{34} \mathrm{Ar}$ & 3.316 & -0.176 & ${ }^{86} \mathrm{Ru}$ & 4.308 & -0.244 & ${ }^{146} \mathrm{Er}$ & 5.014 & -0.207 \\
\hline${ }^{36} \mathrm{Ar}$ & 3.318 & -0.207 & ${ }^{88} \mathrm{Ru}$ & 4.296 & 0.107 & ${ }^{146} \mathrm{Yb}$ & 5.051 & -0.251 \\
\hline${ }^{34} \mathrm{Ca}$ & 3.393 & 0.000 & ${ }^{90} \mathrm{Ru}$ & 4.294 & 0.113 & ${ }^{148} \mathrm{Yb}$ & 5.048 & -0.207 \\
\hline${ }^{36} \mathrm{Ca}$ & 3.375 & 0.000 & ${ }^{90} \mathrm{Pd}$ & 4.339 & 0.109 & ${ }^{150} \mathrm{Yb}$ & 5.049 & -0.180 \\
\hline${ }^{38} \mathrm{Ca}$ & 3.373 & 0.000 & ${ }^{92} \mathrm{Pd}$ & 4.336 & 0.112 & ${ }^{152} \mathrm{Hf}$ & 5.078 & -0.163 \\
\hline${ }^{40} \mathrm{Ti}$ & 3.524 & 0.001 & ${ }^{94} \mathrm{Pd}$ & 4.330 & 0.071 & ${ }^{154} \mathrm{Hf}$ & 5.062 & -0.009 \\
\hline${ }^{42} \mathrm{Ti}$ & 3.506 & 0.000 & ${ }^{94} \mathrm{Cd}$ & 4.371 & 0.071 & ${ }^{156} \mathrm{Hf}$ & 5.089 & -0.090 \\
\hline${ }^{44} \mathrm{Ti}$ & 3.497 & 0.000 & ${ }^{96} \mathrm{Cd}$ & 4.363 & 0.003 & ${ }^{156} \mathrm{~W}$ & 5.094 & -0.006 \\
\hline${ }^{44} \mathrm{Cr}$ & 3.607 & 0.000 & ${ }^{98} \mathrm{Cd}$ & 4.357 & 0.001 & ${ }^{158} \mathrm{~W}$ & 5.117 & -0.066 \\
\hline${ }^{46} \mathrm{Cr}$ & 3.586 & -0.004 & ${ }^{98} \mathrm{Sn}$ & 4.394 & 0.001 & ${ }^{160} \mathrm{~W}$ & 5.143 & 0.110 \\
\hline${ }^{48} \mathrm{Cr}$ & 3.603 & 0.225 & ${ }^{100} \mathrm{Sn}$ & 4.388 & 0.001 & ${ }^{160} \mathrm{Os}$ & 5.142 & 0.022 \\
\hline
\end{tabular}




\begin{tabular}{ccccccccc}
${ }^{46} \mathrm{Fe}$ & 3.666 & 0.003 & ${ }^{102} \mathrm{Sn}$ & 4.411 & 0.002 & ${ }^{162} \mathrm{Os}$ & 5.166 & -0.083 \\
${ }^{48} \mathrm{Fe}$ & 3.649 & 0.084 & ${ }^{106} \mathrm{Te}$ & 4.514 & 0.120 & ${ }^{164} \mathrm{Os}$ & 5.189 & 0.106 \\
${ }^{50} \mathrm{Fe}$ & 3.655 & 0.212 & ${ }^{108} \mathrm{Te}$ & 4.535 & 0.142 & ${ }^{164} \mathrm{Pt}$ & 5.193 & -0.056 \\
${ }^{50} \mathrm{Ni}$ & 3.673 & 0.000 & ${ }^{110} \mathrm{Te}$ & 4.553 & 0.153 & ${ }^{166} \mathrm{Pt}$ & 5.212 & 0.061 \\
${ }^{52} \mathrm{Ni}$ & 3.654 & 0.001 & ${ }^{110} \mathrm{Xe}$ & 4.600 & 0.177 & ${ }^{168} \mathrm{Pt}$ & 5.229 & 0.066 \\
${ }^{54} \mathrm{Ni}$ & 3.639 & 0.000 & ${ }^{112} \mathrm{Xe}$ & 4.617 & 0.195 & ${ }^{170} \mathrm{Hg}$ & 5.254 & -0.006 \\
${ }^{56} \mathrm{Zn}$ & 3.810 & 0.154 & ${ }^{114} \mathrm{Xe}$ & 4.636 & 0.221 & ${ }^{172} \mathrm{Hg}$ & 5.270 & -0.001 \\
${ }^{58} \mathrm{Zn}$ & 3.769 & -0.001 & ${ }^{114} \mathrm{Ba}$ & 4.680 & 0.230 & ${ }^{174} \mathrm{Hg}$ & 5.283 & -0.030 \\
${ }^{60} \mathrm{Zn}$ & 3.800 & 0.170 & ${ }^{116} \mathrm{Ba}$ & 4.717 & 0.285 & ${ }^{176} \mathrm{~Pb}$ & 5.303 & 0.000 \\
${ }^{62} \mathrm{Ge}$ & 3.888 & 0.197 & ${ }^{118} \mathrm{Ba}$ & 4.731 & 0.295 & ${ }^{178} \mathrm{~Pb}$ & 5.313 & 0.001 \\
${ }^{64} \mathrm{Ge}$ & 3.904 & 0.217 & ${ }^{118} \mathrm{Ce}$ & 4.783 & 0.315 & ${ }^{180} \mathrm{~Pb}$ & 5.322 & 0.003 \\
${ }^{66} \mathrm{Ge}$ & 3.931 & -0.261 & ${ }^{120} \mathrm{Ce}$ & 4.796 & 0.326 & & & \\
${ }^{64} \mathrm{Se}$ & 3.976 & 0.205 & ${ }^{122} \mathrm{Ce}$ & 4.805 & 0.328 & & & \\
${ }^{66} \mathrm{Se}$ & 3.997 & -0.265 & ${ }^{122} \mathrm{Nd}$ & 4.847 & 0.341 & & & \\
\hline \hline
\end{tabular}




\section{FIGURES}

FIG. 1. Calculated two-proton separation energies $S_{2 p}$ for the $N=8-94$ isotones as a function of the proton number $Z$.

FIG. 2. Calculated quadrupole deformation parameters $\beta_{2}$ of the most proton-rich, proton-stable, even-even nuclei with proton numbers from $Z=10$ to $Z=82$. 


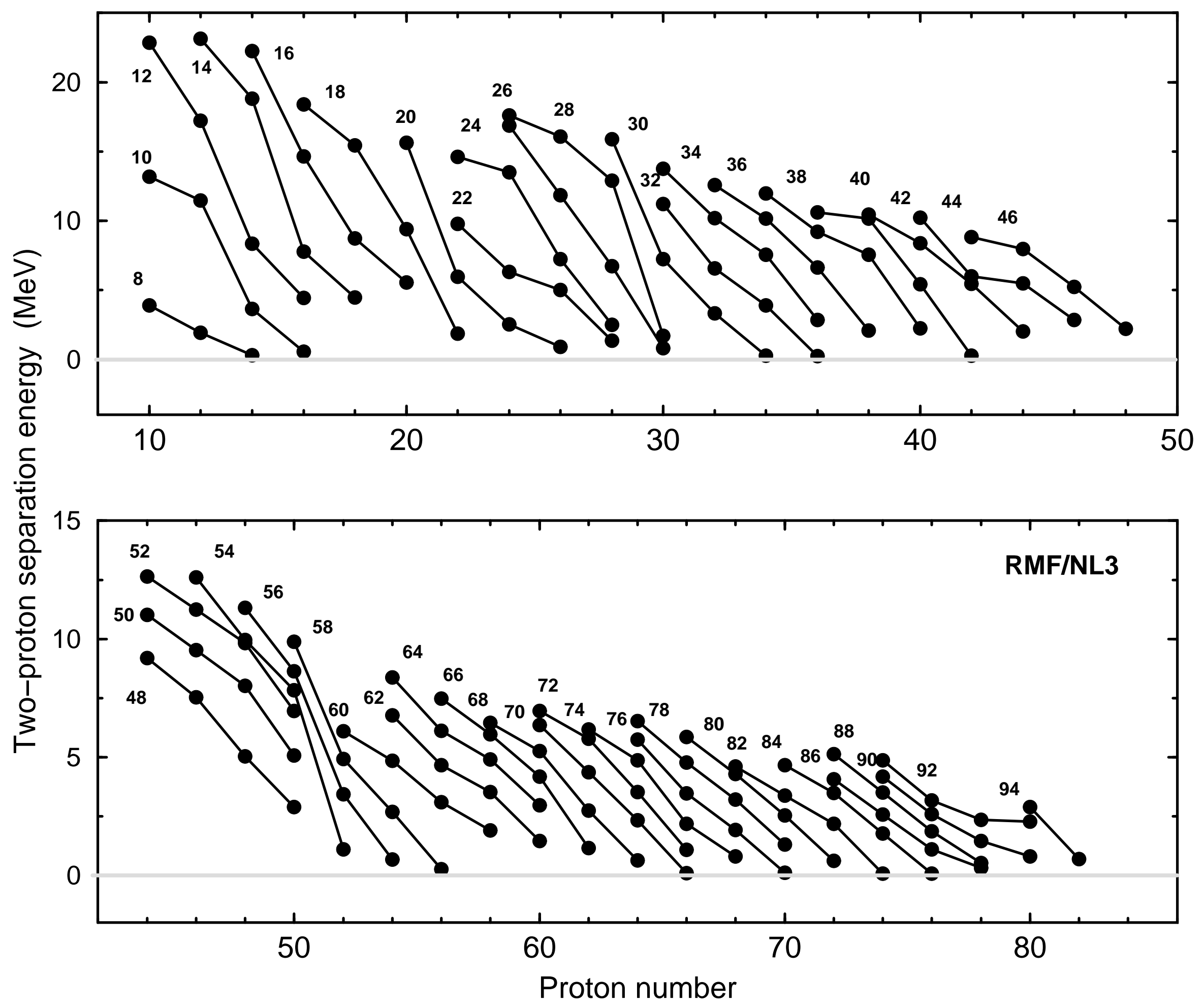




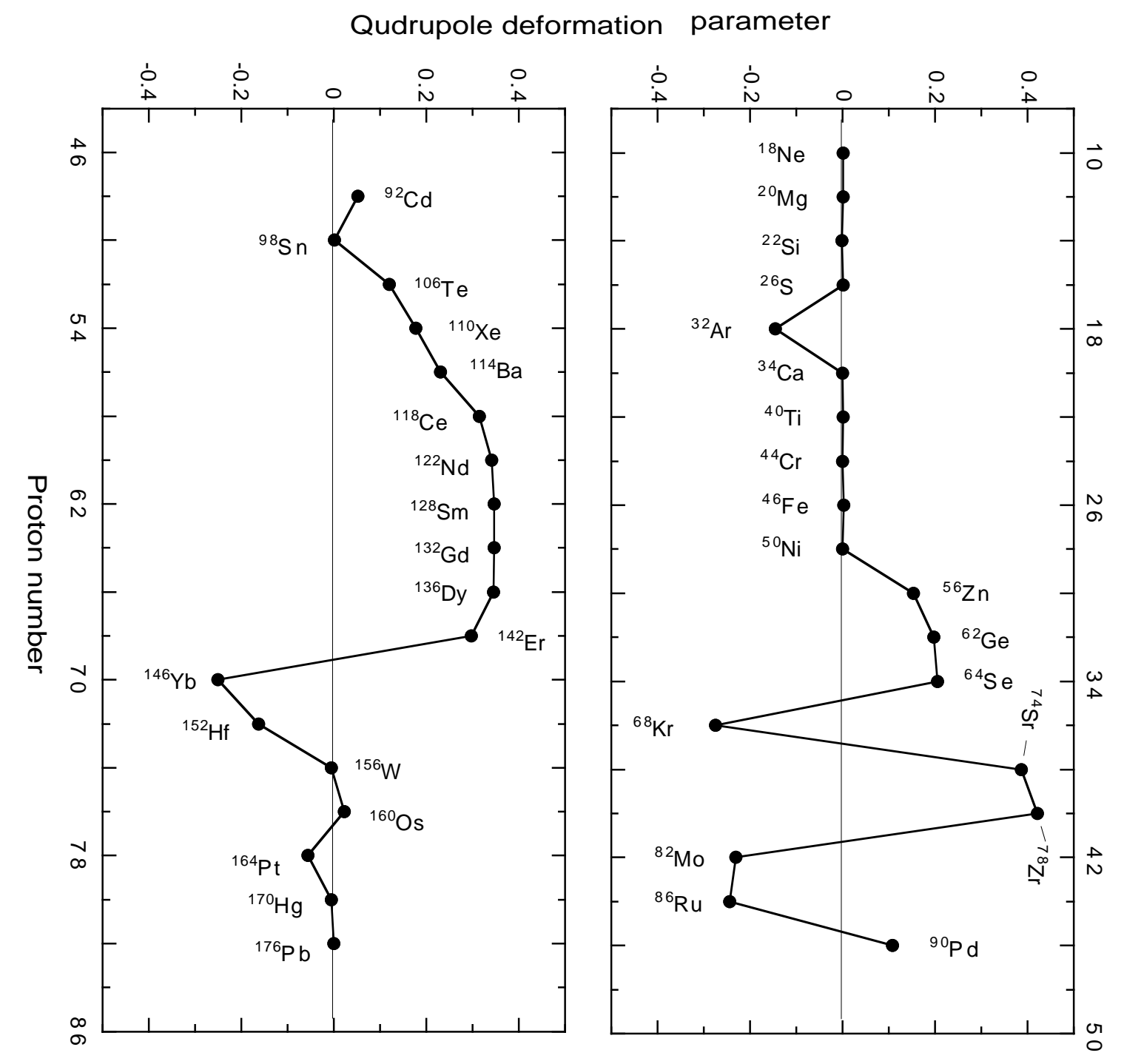

